\title{
Patient compliance and locus of control in orthodontic treatment: A prospective study
}

\author{
Shin-Jae Lee, ${ }^{a}$ Sug-Joon Ahn, ${ }^{\text {b }}$ and Tae-Woo Kim ${ }^{c}$ \\ Seoul, Korea
}

Introduction: Increased understanding of orthodontic patients will improve communication between dentist and patient; this is important for an optimal treatment outcome. In this prospective study, we addressed the relationship between patient compliance and locus of control (LOC) characteristics and evaluated posttreatment changes in LOC profiles. Methods: Two types of LOC questionnaires, the Rotter internal control scale (RICS) and the Nowicki-Strickland external control scale (NSECS), were given to 561 patients before conventional orthodontic treatment. After orthodontic treatment, the same questionnaires were readministered, and patient compliance was evaluated by an orthodontist and 3 dental hygienists. LOC scores were calculated at the end of the examination period. The difference in LOC between the good and poor compliance groups, and the posttreatment changes in LOC were evaluated. Results: There was no significant difference in RICS and NSECS profiles between the good and poor compliance groups. NSECS decreased significantly after orthodontic treatment, but there were no significant changes in RICS. Conclusions: Patient compliance appears to be a complex factor that cannot be predicted by LOC evaluation before orthodontic treatment. Patients who underwent orthodontic treatment showed decreased external control dispositions. (Am J Orthod Dentofacial Orthop 2008;133:354-8)

$\mathbf{P}$ atient compliance is a major problem in orthodontics. Therefore, if a brief psychological survey could anticipate compliance problems during orthodontic treatment, it would help clinicians to understand and communicate with their patients. The locus of control (LOC) scale has proved to be extremely useful in the prediction of various human behaviors. The concept of LOC refers to the tendency to perceive one's reinforcements as either a consequences of one's own behavior or due to extrinsic factors. ${ }^{1}$ The effects of reward or reinforcement on preceding behavior depend in part on whether the person perceives the reward as contingent on his or her own behavior or independent of it. Those who believe that they exercise some control over their destinies are considered to be internally controlled and to have an internal LOC. In contrast, some patients believe that the attainment of a reward not only depends on their work or initiative but is also largely contingent on factors

\footnotetext{
From the Department of Orthodontics, School of Dentistry and Dental Research Institute, Seoul National University, Seoul, Korea.

${ }^{\mathrm{a}}$ Associate professor.

${ }^{\mathrm{b}}$ Assistant professor.

${ }^{\mathrm{c}}$ Chairman and professor.

Reprint requests to: Sug-Joon Ahn, Department of Orthodontics, School of Dentistry and Dental Research Institute, Seoul National University, 28-22 Yunkeun-Dong, Jongro-Gu, Seoul 110-744, Korea (ROK); e-mail, titoo@ snu.ac.kr.

Submitted, December 2005; revised and accepted, March 2006. 0889-5406/\$34.00

Copyright (C) 2008 by the American Association of Orthodontists. doi:10.1016/j.ajodo.2006.03.040
}

outside their control; in other words, the reward was the result of luck, chance, or fate; controlled by others; or unpredictable because of the great complexity of the forces surrounding them. This interpretation is labeled as belief in external control, and the patient is considered to have an external LOC. ${ }^{2}$

LOC has been studied in many subjects to enhance the understanding and prediction of human behaviors, especially those affecting health. ${ }^{3}$ In dentistry, LOC studies have been used to enhance oral hygiene, ${ }^{4-6}$ to evaluate prognosis of periodontal treatment, ${ }^{7}$ and to investigate the relationship between LOC and craniomandibular dysfunction. ${ }^{8}$ More specifically, a LOC scale, introduced for orthodontic patients and their parents, has been shown to be a valid and reliable tool for orthodontist-patient communication. ${ }^{9}$ Thus, LOC was expected to be a useful tool to enhance patient compliance in orthodontic treatment.

It has been suggested that there is a linear relationship between internal or external LOC and patient adjustment, with external patients tending to be more maladjusted than internal ones. ${ }^{10}$ Moreover, an internal control disposition is associated with different social behavior, higher academic performance, and other achievement-related activities. ${ }^{11,12}$ Patients who have internal LOC are known to adapt faster, have less pain during orthodontic treatment, ${ }^{13}$ and tend to cooperate better than those with an external LOC. ${ }^{14}$ However, they also more actively express their complaints about 
treatment ${ }^{15,16}$; this can make an unfavorable impression on clinical staff. Because patient compliance is an important prerequisite for a positive treatment outcome in orthodontics, it was considered valuable to determine whether patient compliance can be predicted by a relatively simple survey before treatment. ${ }^{17-19}$ Thus, our first aim in this prospective investigation was to analyze the relationship between patient compliance and LOC characteristics.

The second aspect of this study addressed quantification of the influence of orthodontic treatment on patient psychology. Orthodontic treatment is expensive and demands effort from the patient. The perceived benefits of orthodontic treatment are increased regularity of the dental arches and a more favorable appearance. $^{20}$ These benefits might elicit favorable feedback, which in turn reinforces the internal control disposition. Subjects with a previous history of orthodontic treatment have been reported to show greater internal control than those who had not previously been treated. ${ }^{21}$ However, because those who decide to have their malocclusion treated have been found to have greater internal control than average, ${ }^{15}$ it is necessary to determine whether the increased internal control resulted from the treatment or was determined by their personality traits. It has been reported that general psychosocial responses are not influenced by orthodontic treatment. ${ }^{22}$ Therefore, our second aim was to evaluate prospectively the change in LOC characteristics between pretreatment and posttreatment.

\section{MATERIAL AND METHODS}

The study included 561 subjects who were consecutively treated by the first author (S.J.L.) and 3 dental hygienists in a private orthodontic office in a metropolitan middle-class area in western Seoul, Korea, between 1997 and 2002. The subjects included 195 males and 366 females with a mean age of $16.4 \pm 6.5$ years. Patients with planned orthognathic surgery or esthetic plastic surgery were excluded to eliminate the psychological influence of surgical intervention. The inclusion criteria were similar to those of previous research ${ }^{20}$ : moderately severe to severe malocclusion with an esthetic impairment, educational level equivalent to elementary school, no significant previous or concomitant organic or psychiatric disease, and agreement to participate in a longitudinal study. The average treatment time was $2.1 \pm 0.5$ years.

Two types of LOC questionnaires were administered before and after orthodontic treatment. One measured attitude characteristics for internal control orientation based on the Rotter internal control scale (RICS) ${ }^{1}$ comprising 29 items (including 6 filler items). Example items of the scale are "People's misfortunes result from the mistakes they make" and "One of the major reasons why we have wars is because people don't take enough interest in politics." This scale was translated into Korean and then tested for comprehension; minor changes in the wording were made, resulting in 15 items with 6 filler items on the basis of the response ratio and an internal consistency correlation for each item. $^{23}$

The second questionnaire was designed to measure the magnitude of external control, based on the NowickiStrickland external control scale (NSECS), ${ }^{24}$ a paper-andpencil measure consisting of 40 yes or no questions. Examples of items on the scale are "Do you believe that most problems will solve themselves if you don't interfere with them?" and "Are you often blamed for things that just aren't your fault?" The original scale was translated, and the response ratio, internal consistency, and reliability were tested; this finally resulted in 40 items. $^{25}$

At the end of active orthodontic treatment, patient compliance was evaluated independently by the orthodontist (S.J.L.) and 3 hygienists, since measurement of compliance is both subjective and sensitive. The orthodontist, a male dentist, has been in clinical orthodontic practice for over 14 years. The hygienists had over 6 years experience each in a clinical orthodontic practice. The opinions of the hygienists were combined. The following criteria were used to define compliance: oral hygiene, keeping appointments, and wearing of appliances, including extraoral anchorage devices and intraoral elastics. Originally, each subject was evaluated on a 5-point Likert scale, but the data were recoded on a 3-point scale (good, fair, and poor), because there were few extreme scores. Finally, the good and fair groups were unified as the good compliance group, and the subjects were assigned to either the good compliance or the poor compliance group for ease of interpretation. These data transformations were shown to have no effect on the main result of the study (data not shown).

The RICS and the NSECS were readministered at the end of treatment. The cumulative scores of the questionnaires were not checked and calculated until the end of data collection to prevent observer bias between patient compliance and LOC characteristics.

\section{Statistical analysis}

After the data were collected, an inferential test with mixed model analysis of variance (ANOVA) was performed for both sex differences and age covariates; it showed no significant effects of those confounding variables. After checking the assumption of homoscedasticity and normality, an independent $t$ test was therefore used to evaluate the difference in LOC between the good and poor compliance groups. The 
Table I. Cross tabulation of patient compliance by evaluators

\begin{tabular}{|c|c|c|c|c|}
\hline \multirow[b]{2}{*}{$n=561$} & \multicolumn{3}{|c|}{$\begin{array}{c}\text { Orthodontist's evaluation of patients' } \\
\text { compliance }\end{array}$} & \multirow[b]{2}{*}{ Significant results } \\
\hline & Good & Poor & Total & \\
\hline \multicolumn{5}{|c|}{ Hygienists' evaluation of patients' compliance } \\
\hline Good & $65.9 \%$ & $15.0 \%{ }^{\mathrm{A}}$ & $80.9 \%$ & $\mathrm{~A}>\mathrm{B}^{*}(P<.001)$ \\
\hline Poor & $8.2 \%^{\mathrm{B}}$ & $10.9 \%$ & $19.1 \%$ & \\
\hline Total & $74.1 \%$ & $25.9 \%$ & $100.0 \%$ & $\kappa=0.34^{\dagger}(P<.001)$ \\
\hline
\end{tabular}

paired $t$ test was used to evaluate the difference between pretreatment and posttreatment LOC. The results of the RICS and the NSECS were compared with normative data available for Korean samples, ${ }^{23,26}$ by using the Student $t$ test with estimated population standard error of the difference and pooled variance estimates. The measure of agreement between the orthodontist and the dental hygienists about patients' compliance was analyzed with the kappa statistic. The McNemar test for the contingency table was used to determine whether the subjects were equally likely to fall into either contradictory classification category.

\section{RESULTS}

Sex and age covariates had no statistically significant effect on the 2 types of LOC scale, the RICS and the NSECS. As expected, the RICS and the NSECS showed negative correlation, $\mathrm{r}=-0.386(P<.001)$, because of their opposing concepts.

When compared with previous studies that evaluated the RICS and the NSECS for the general population, ${ }^{23,26}$ our subjects showed higher internal control scores (mean RICS, 9.45; age, 20-30; number of subjects, $33^{23}$ ) and lower external control scores (mean NSECS, 17.51; age, 8-19; number of subjects, $690^{26}$ ).

About $74 \%$ of the patients were classified as compliant by the orthodontist, and about $81 \%$ were classified as compliant by the hygienists. Although the kappa statistic was significant $(\kappa, 0.34 ; P<.001)$, the measure of agreement for patient compliance showed poor marginal agreement between the orthodontist and the hygienists. The McNemar test for the contingency table showed that, among subjects who were classified differently, they were not evenly split $(P<.001)$. It was apparent that the hygienists considered more patients compliant than did the orthodontist (Table I).

Table II shows no statistically significant difference between the good and poor compliance groups in either the RICS or the NSECS profile.

The paired $t$ test showed that the NSECS score was
Table II. Relationship between patient compliance and LOC scale

\begin{tabular}{llllll}
\hline & \multicolumn{2}{c}{$R I C S$} & & \multicolumn{2}{c}{ NSECS } \\
\cline { 2 - 3 } \cline { 5 - 6 }$n=561$ & $($ mean $\pm S D)$ & $\mathrm{P}^{*}$ & & $($ mean $\pm S D)$ & $\mathrm{P}^{*}$ \\
\hline $\begin{array}{l}\text { Overall } \\
\text { Orthodontist }\end{array}$ & $10.47 \pm 2.29$ & & $12.33 \pm 3.99$ & \\
$\quad$ Good & $10.46 \pm 2.24$ & .196 & & $12.26 \pm 3.87$ & .822 \\
$\quad \begin{array}{l}\text { Poor } \\
\text { Hygienists }\end{array}$ & $10.65 \pm 2.40$ & & & $12.32 \pm 4.21$ & \\
$\quad$ Good & $10.44 \pm 2.33$ & .306 & & $12.29 \pm 3.97$ & .438 \\
$\quad$ Poor & $10.62 \pm 2.27$ & & $12.51 \pm 4.09$ & \\
\hline
\end{tabular}

*Statistical significance between good and poor compliance groups was tested by independent $t$ test.

Table III. Change in the LOC between pretreatment and posttreatment

\begin{tabular}{llll}
\hline$n=561$ & $\begin{array}{c}\text { Pretreatment } \\
(\text { mean } \pm S D)\end{array}$ & $\begin{array}{c}\text { Posttreatment } \\
(\text { mean } \pm S D)\end{array}$ & P* \\
\hline RICS & $10.44 \pm 2.26$ & $10.57 \pm 2.32$ & .345 \\
NSECS & $12.62 \pm 3.97$ & $11.71 \pm 3.98$ & .001 \\
\hline
\end{tabular}

*Statistical significance before and after orthodontic treatment was tested by paired $t$ test.

lower after orthodontic treatment $(P<.001)$, whereas the RICS score was unchanged (Table III).

\section{DISCUSSION}

Some psychological inventories have already been proven to be related to compliance in adolescent orthodontic patients. ${ }^{17,18,27}$ Among the various psychological inventories, the LOC scale has proved particularly useful, especially in the prediction of healthenhancing behavior. ${ }^{3-8}$ This study was inspired by a previous report that concluded that LOC information might be useful to enhance patient compliance in orthodontic treatment. ${ }^{9}$ Although a specific LOC questionnaire for orthodontic patients ${ }^{9}$ is available, there were 3 reasons for selecting the RICS and the NSECS 
in this study: (1) the RICS and the NSEC have already been used many times in their translated forms with proven reliability and validity for the general population and orthodontic patients ${ }^{15,16,23-26}$; (2) a minimum elementary level of education is required for use; and (3) these tests are practical for use in clinical practice with free distribution and rapid completion, and most patients can complete them in 15 minutes.

The initial alternative hypothesis of this study stated that patient compliance is related to the patient's LOC and thus could be predicted by an LOC survey before treatment. However, the results did not support the hypothesis that there is a relationship between the LOC and patient compliance, even though the number of subjects was large enough to prevent type II errors that are always problematic when an alternative hypothesis is rejected.

Theoretically, one would expect some relationship between internality and good compliance in orthodontic practice. Patients who have an internal control inclination are known to adapt faster and have less pain during orthodontic treatment, ${ }^{13}$ but, because they also complain freely, they can create an unfavorable impression on the clinical staff. ${ }^{15,16}$ The assessment of patient compliance is primarily the rater's subjective opinion. Therefore, evaluation of patient compliance by the orthodontist and the clinical staff might, to some extent, reflect their personal impressions of the patient.

It is also likely that patient compliance is complex and cannot be explained by LOC characteristics alone. A previous study of patient compliance for wearing of appliances reported little consistency among various compliance indicators, such as keeping appointments, oral hygiene habits, and appliance maintenance. ${ }^{28} \mathrm{It}$ was also found that orthodontic compliance does not involve a single general dimension of compliance. For example, a patient who is a good brusher is not necessarily a good headgear wearer, and vice versa. ${ }^{18}$ Although measurement of compliance has been attempted with reliable systems such as built-in timing devices in various appliances, ${ }^{29-32}$ these could only measure appliance wear time objectively. Some research has focused on the effect of sex differences and ages on compliance with appliance wear. ${ }^{19,32,33}$ One study found that prepubertal patients $(<12$ years of age) were more compliant than other age groups in wearing the appliances but less compliant in keeping appointments or protecting appliances from breakage. ${ }^{33}$ Thus, although quantitative assessments of patient compliance have measured tasks such as appointment keeping, appliance wear, interest in treatment, and adequate oral hygiene, ${ }^{27}$ other factors can influence patient compliance, making accurate measurement a truly challenging task.
The conclusion that patient compliance cannot be predicted by the LOC does not nullify the usefulness of the LOC measure. In practice, the proposal of Tedesco et al, ${ }^{9}$ emphasizing that orthodontist-patient communication should be adjusted according to the LOC characteristics of the patient, has proved to be useful. For example, for a rebellious adolescent patient with high internal LOC, the cause-effect relationship between compliance and progress toward the treatment goal should be emphasized consistently by the orthodontist. ${ }^{9}$

This study showed that the hygienists' evaluations of patients' compliances were more generous than those of the orthodontist. The cause of disagreement might have originated from the psychological dynamic between the patient and the rater. In general, patients see the orthodontist as the authority figure rather than the hygienist. Therefore, the disagreement of the orthodontist and the hygienists might reflect their different viewpoints. It is also possible that an uncomplicated treatment can give the orthodontist a favorable impression of the patient, and posttreatment assessment of patient compliance is influenced by this impression. An orthodontist not only is influenced by the patient's appointment keeping and obedience, but also is more sensitive to and responsible for the quality of treatment. This might explain why the orthodontist more critically assessed compliance than did the hygienists.

The subjects who completed posttreatment LOC questionnaires showed changes only in the NSECS variables; there was no significant change in the RICS scores. This difference might be explained in part by the nature of the scales; the RICS consists of only 15 items (6 items were fillers), whereas the NSECS consists of 40 items; this could have resulted in greater discrimination.

Subjects with advantageous dental esthetics appeared to develop more acute dentofacial awareness and hold stronger beliefs that dental appearance is important for a healthy appearance and successful social interactions. ${ }^{21}$ The time and cost of orthodontic treatment produces significant posttreatment benefits such as improved esthetics, and social and psychological well-being. This, in turn, might reinforce autonomy and responsibility for self, including one's own oral health.

The subjectivity of the compliance measure is a major limitation of this study. Further studies are required with more objective variables, such as an index of orthodontic treatment need, ${ }^{34,35}$ more objective indicators of compliance, ${ }^{36}$ and a patient satisfaction scale, ${ }^{37}$ to increase understanding of the roles of patient compliance and psychology in orthodontic treatment. 


\section{CONCLUSIONS}

Orthodontic treatment requires a high technical standard; however, patient psychology and compliance are considered equally important factors in the treatment protocol. Patient compliance appears to be a complex issue that cannot easily be predicted before treatment by LOC questionnaires. Patients who underwent orthodontic treatment showed reduced external control characteristics than before treatment; this can be interpreted as an incidental psychological gain through orthodontic treatment. These findings warrant further studies of patient compliance and the psychology of orthodontic treatment.

We thank Young-Ho Kim (Associate Professor, Department of Orthodontics, Samsung Medical Center) for his contributions to this research.

\section{REFERENCES}

1. Rotter JB. Generalized expectancies for internal versus external control of reinforcement. Psychol Monogr 1966;80:1-28.

2. Rotter JB. Some implications of a social learning theory for the prediction of goal directed behavior from testing procedures. Psychol Rev 1960;67:301-16.

3. Kneckt MC, Syrjala AM, Knuuttila ML. Locus of control beliefs predicting oral and diabetes health behavior and health status. Acta Odontol Scand 1999;57:127-31.

4. Macgregor ID, Regis D, Balding J. Self-concept and dental health behaviours in adolescents. J Clin Periodontol 1997;24:335-9.

5. Kallio P, Murtomaa H. Determinants of self-assessed gingival health among adolescents. Acta Odontol Scand 1997;55:106-10.

6. Wolfe GR, Stewart JM. Maeder LA, Hartz GW. Use of dental coping beliefs scale to measure cognitive changes following oral hygiene interventions. Community Dent Oral Epidemiol 1996;24:37-41.

7. Borkowska ED, Watts TL, Weinman J. The relationship of health beliefs and psychological mood to patient adherence to oral hygiene behaviour. J Clin Periodontol 1998;25:187-93.

8. de Leeuw JR, Steenks MH, Ros WJ, Bosman F, Winnubst JA, Scholte AM. Psychosocial aspects of craniomandibular dysfunction. An assessment of clinical and community findings. J Oral Rehabil 1994;21:127-43.

9. Tedesco LA, Albino JE, Cunat JJ. Reliability and validity of the orthodontic locus of control scale. Am J Orthod 1985;88:396-401.

10. Joe VC. Review of the internal-external control construct as a personality variable. Psychol Rep 1971;28:619-40.

11. Nowicki S, Walker $\mathrm{C}$. The role of generalized and specific expectancies in determining academic achievement. J Soc Psychol 1974;94:275-80.

12. Lefcourt HM. Internal versus external control of reinforcement; a review. Psychol Bull 1966;65:206-20.

13. Sergl HG, Klages U, Zentner A. Pain and discomfort during orthodontic treatment: causative factors and effects on compliance. Am J Orthod Dentofacial Orthop 1998;114:684-91.

14. Albino JE, Lawrence SD, Lopes CE, Nash LB, Tedesco LA. Cooperation of adolescents in orthodontic treatment. J Behav Med 1991;14:53-70.

15. Lee SJ. Relationship between locus of control and treatment compliance in adult orthodontic patients. Korean J Orthod $2002 ; 32: 71-8$
16. Kim YH, Bae C. The relationship between locus of control and the discomfort of the patients at the initial stage of the orthodontic treatment. Korean J Orthod 1994;24:1-15.

17. Cucalon A 3rd, Smith RJ. Relationship between compliance by adolescent orthodontic patients and performance on psychological tests. Angle Orthod 1990;60:107-14.

18. El-Mangoury NH. Orthodontic cooperation. Am J Orthod 1981; 80:604-22.

19. Southard KA, Tolley EA, Arheart KL, Hackett-Renner CA, Southard TE. Application of the Millon Adolescent Personality Inventory in evaluating orthodontic compliance. Am J Orthod Dentofacial Orthop 1991;100:553-61.

20. Varela M, Garcia-Camb JE. Impact of orthodontics on the psychologic profile of adult patients: a prospective study. Am J Orthod Dentofacial Orthop 1995;108:142-8.

21. Klages U, Bruckner A, Guld Y, Zentner A. Dental esthetics, orthodontic treatment, and oral-health attitudes in young adults. Am J Orthod Dentofacial Orthop 2005;128:442-9.

22. Albino JE, Lawrence SD, Tedesco LA. Psychological and social effects of orthodontic treatment. J Behav Med 1994;17:81-98.

23. Cha JH, Kong CJ, Kim CS. Report on construction of an internal-external control scale. Korean Institute for Research in the Behavioral Sciences Research Note 1973;2:263-71.

24. Nowicki S, Strickland BR. A locus of control scale for children. J Consult Clin Psychol 1973;40:148-54.

25. Jung EJ, Sohn JH. Report on construction of internal-external control scale using Nowicki and Strickland (1973)'s scale. Korean Institute for Research in the Behavioral Sciences Research Note 1981;10:1-18.

26. Hong KE, Kwon YT, Chang KJ. Locus of control and family environmental variables in primary, middle and high school students. Seoul J Psychiatry 1988;13:37-44.

27. Slakter MJ, Albino JE, Fox RN, Lewis EA. Reliability and stability of the orthodontic patient cooperation scale. Am J Orthod 1980;78:559-63.

28. Bartsch A, Witt E, Dietz I, Dietz P. The clinical and psychological indicators of behavior in wearing a removable appliance. Fortschr Kieferorthop 1993;54:119-28.

29. Cole WA. Accuracy of patient reporting as an indication of headgear compliance. Am J Orthod Dentofacial Orthop 2002;121:419-23.

30. Bartsch A, Witt E, Sahm G, Schneider S. Correlates of patient compliance with removable appliance wear. Am J Orthod Dentofacial Orthop 1993;104:378-86.

31. Cureton SL, Regenniter FJ, Yancey JM. Clinical vs quantitative assessment of headgear compliance. Am J Orthod Dentofacial Orthop 1993;104:277-84.

32. Clemmer EJ, Hayes EW. Patient cooperation in wearing orthodontic headgear. Am J Orthod 1979;75:517-24.

33. Weiss J, Eiser HM. Psychological timing of orthodontic treatment. Am J Orthod 1977;72:198-204.

34. Savastano NJ Jr, Firestone AR, Beck FM, Vig KWL. Validation of the complexity and treatment outcome components of the index of complexity, outcome, and need (ICON). Am J Orthod Dentofacial Orthop 2003;124:244-8.

35. Brook PH, Shaw WC. The development of an index of orthodontic treatment priority. Eur J Orthod 1989;11:309-20.

36. Egolf R, BeGole EA, Upshaw HS. Factors associated with orthodontic patient compliance with intraoral elastic and headgear wear. Am J Orthod Dentofacial Orthop 1990;97:336-48.

37. Bennett ME, Tulloch JF, Vig KW, Phillips CL. Measuring orthodontic treatment satisfaction: questionnaire development and preliminary validation. J Public Health Dent 2001;61:155-60. 